\title{
UMA FUNDAMENTAÇÃO DA NOÇÃO DE EVENTO PARA A LINGÜÍSTICA
}

\author{
Teresa Cristina Wachowicz*
}

\section{Introdução}

om o objetivo de interpretar a língua natural, a semântica formal é a área da lingüística que apresenta propostas com fundamentos lógicos os mais variados possíveis. Esses fundamentos são, na verdade, visões ontológicas que pensam o mundo cada um à sua maneira. Nessa linha de pensamento, uma visão ontológica pressupõe uma representação formal dos significados, mas os caminhos para a construção dessa representação é que são diferentes. Cada caminho resgata um recorte nos modelos lógicos que interage melhor com o seu respectivo objeto de estudo - ou o modo de significação.

A proposta ontológica que nos interessa analisar neste trabalho é a noção de "evento", para fundamentar um tipo de semântica formal que hoje é conhecida

* Universidade Federal do Paraná 
como "semântica de eventos". Trabalhos recentes da área nos mostram que o caminho da representação do significado de sentenças de língua natural baseado em eventos sinalizam interessantes alternativas para o tratamento das modificações adverbiais, das dependências anafóricas, das questões temporais e aspectuais, etc. Mas a idéia geral é que um tratamento de eventos pode, sobretudo, relativizar a tipologia da "aktionsart", ou da classificação vendleriana das sentenças, fundamentalmente com uma perspectiva de composicionalidade do significado. Quer dizer, através de uma noção de evento desenvolvida e complexa, a classificação aspectual das sentenças se dá por uma interação composicional entre as subunidades que compõem o evento.

Tomando, no entanto, essa tarefa essencialmente linguística de classificação composicional dos eventos como um objetivo posterior, assumimos neste trabalho o objetivo de fundamentar inicialmente a noção de evento. Nesse sentido, nossa linha de raciocínio aqui será mais de base filosófica do que lingüística.

É muito comum os trabalhos lingüísticos referirem-se diretamente a Davidson 1980 como base inaugural da noção de evento para a interpretação de lingua natural. Essa referência se justifica pela argumentação fortemente lingüística do autor. No entanto, se nossos objetivos em teoria de eventos se complexificam na proposta da composicionalidade, julgamos ser pertinente uma fundamentação mais abrangente, inclusive interdisciplinar, para uma conceituação desenvolvida de evento. O caminho pelo qual optamos, além de retomar Davidson 1980, foi resgatar as noções de evento para Badiou 1996, da filosofia, e para Santos 1997, da geografia (parte 2). Com base nessa retomada teórica, procuramos construir comparações teóricas que sinalizem alternativas para questões lingüísticas, tais como a leitura aspectual, a noção de sujeito e intencionalidade e a noção de modelo na interpretação de sentenças (parte 3).

\section{O resgate teórico}

\section{Davidson 1980}

Nos primeiros capítulos de Actions and Events, Davidson desenvolve uma longa discussão em torno de uma teoria da ação, em que se insere a idéia de intencionalidade e de agentividade conexas . Para ele, na mais fiel resposta à filosofia analítica, é possível racionalizar a causa de uma ação, ou seja, a causa é racional.

1 Rothstein 1998, Smith 1997, Link 1997. 
No entanto, deixa-se a abertura para o fato de que nem toda causa é ligada à intenção. Em outras palavras, as razões são causas dos atos, mas nem sempre as razões são conhecidas pelos agentes.

Redesenhando as propostas para uma teoria de eventos, Davidson preocupa-se com eventos ligados à ação, embora existam outros tipos de eventos. Uma ação requer agentividade, e agentividade pressupõe intencionalidade. É essa intencionalidade que ancora na ação - extensional - o que antes é tido como um primitivo intensional.

Mais especificamente em relação à teoria das ações, no capítulo 6, Davidson propõe que o evento seja considerado uma entidade individualizável. Tratar logicamente o evento dessa forma significa considerá-lo um argumento de predicado. Antes de sua proposta formal propriamente dita, Davidson percorre dois caminhos: primeiro, ele justifica intuitivamente o tratamento do evento como indivíduo; depois, resgata uma série de autores ${ }^{2}$, analisa-os quanto ao tratamento dado às expressões de ação e quanto ao evento e, por fim, apresenta a sua proposta de abordagem do evento.

Sentenças como John did it slowly, deliberately, in the bathroom, with a knife, at midnight justificam o tratamento lingüístico de eventos. O pronome anafórico em destaque parece se referir a uma entidade, presumivelmente uma ação. Para uma forma lógica da sentença, Davidson propõe que se pense em algo como "há uma ação $x$, tal que João fez x lentamente e João fez x deliberadamente...". 0 objetivo é então o de mostrar como os significados de ação dependem da estrutura da sentença que a denota. Essa estrutura deve ser traduzida em forma de predicados sobre uma variável individual evento.

Antes de partir para abordagens de outros autores, Davidson reduz a sentença acima para John did it in the bathroom, with a knife, at midnight. Advérbios como "slowly" e "deliberately" são considerados intencionais. Logo, não fazem parte da "descrição" do evento, pois não introduzem uma nova entidade à situação, como o fazem as expressões "in the bathroom"(lugar), "with a knife"(instrumento), "at midnight"(tempo). Esse tipo de advérbio, o intencional, faz parte do estado mental do sujeito da ação.

Kenny 1963 apresenta uma proposta diferente. A sentença John did it slowly, deliberately, in the bathroom, with a knife, at midnight é tida como um predicado de cinco lugares, cujos argumentos são preenchidos pelos advérbios intencionais e outras expressões modificadoras (de tempo, lugar, instrumento, etc.). É o que Kenny chamou de "poliadicidade variável" dos verbos de ação. Davidson concorda com Kenny na medida em que não se pode pensar os verbos de ação como predicados Davidson 1980.

2 Kenny 1963, Chisholm 1964, Von Wright 1963, Scheffler 1963 e Reichenbach 1947, apud 
WACHOWICZ T. C. Uma fundamentação da noção...

com argumentos fixos, mas discorda em pensar que esses argumentos podem ser criados indefinidamente. Discorda também na viabilidade de representação dos advérbios intencionais.

Chisholm 1964, em outro rumo da análise, discute a idéia de restringir os verbos de ação à propriedade de mudança de estados. Para o autor os verbos de ação podem denotar mudanças ou não-mudanças de "estados de coisas". Von Wright 1963, por sua vez, apresentará uma estrutura mais complexa da descrição da mudança de evento, na medida em que ele inclui à descrição o estado inicial. A sentença de ação, segundo Von Wright, se formaliza da seguinte forma: $x$ brings it about that a state where $p$ changes into a state where $q$. Davidson julga essa proposta redutora, pois em uma sentença como I walk from San Francisco to Pittsburgh, a forma seria a mesma para as ações de voar, andar ou dirigir.

O mérito de Von Wright foi, contudo, o de introduzir a distinção entre "ação" e "evento". Segundo ele, a ação é a origem de um evento. Davidson não aprova essa distinção; o que lhe importa é encontrar a forma lógica diferente para as sentenças de ação. Aí reside seu paralelo: o evento é a tradução lógica da ação.

Davidson aponta que o problema das abordagens acima é que o evento não ganha o estatuto separado, distinto, que é pautado por fatos lingüísticos reais. Ou seja, o evento deve ser tratado como uma entidade individual. Em Reichenbach 1947, essa perspectiva é de certa forma contemplada. A sentença Amundsen flew to the North Pole, para ele, é logicamente equivalente a $\$ \mathrm{x}$ (x consists in the fact that Amundsen flew to the North Pole). A expressão is an event that consists in the fact that é vista como um operador que, prefixando a sentença, forma um predicado de evento. Se acrescentarmos informações à sentença acima (Amundsen flew to the North Pole in May 1926), a proposta de tradução pode apresentar solução ao problema da poliadicidade de Kenny. Agora, os eventos são entidades sobre as quais um número infinito de coisas pode ser dito. Logicamente, essa alternativa é certamente mais viável: \$x (x consists in the fact that Amundsen flew to North Pole and $\mathrm{x}$ took place in May 1926) (e assim por diante).

O traço importante de Reichenbach é que a sentença de ação ganha a leitura existencial única; quer dizer, não há um conjunto de eventos a ser descrito, o que há é um evento único, sobre o qual atuam predicados. A fórmula de Reichenbach não descreve exatamente um evento, mas quer dizer que há um evento que a torna verdadeira. É importante frisar esse raciocínio aqui, pois irá convergir com a noção de evento de Badiou. Em Reichenbach, o evento, definitivamente, ganha estatuto de entidade.

Finalmente, Davidson aponta sua proposta de tratamento às sentenças de ação que, segundo ele, combina os méritos das propostas resenhadas e evita dificuldades latentes. A idéia básica é a de que verbos de ação são verbos que dizem o que alguém fez com agentividade e intenção. Uma sentença como Shem kicked Shaun é 
WACHOWICZ T. C. Uma fundamentação da noçāo...

tradicionalmente tida como um predicado de dois lugares, mas Davidson propõe, agora, um predicado de três lugares: $\exists \mathrm{x}$ (kicked (Shem, Shaum, $\mathrm{x}$ )), com a variável $\mathrm{x}$ denotando o evento.

Por fim, Davidson encerra sua apresentação colocando os pontos que definem o predicado de ação: a atribuição de agente a um dos argumentos do verbo, sendo esta pessoa alguém que age intencionalmente. A intencionalidade é tida aqui como traço da agentividade, e não como advérbio da sentença de ação. Outro ponto importante, sobretudo sob a perspectiva lingüística: há outros predicados que não predicam sobre eventos.

\section{Badiou 1996}

Inicialmente, Badiou faz uma apresentação genérica do atual estado da filosofia, em que reconhece três grandes vertentes: a fenomenologia de Heidegger, as filosofias pautadas na lógica matemática, e as filosofias de doutrina pós-cartesiana do sujeito, que se dividem em duas: as políticas (marcadas pelos nomes de Marx e Lenin) e as mentais (marcadas por Freud e Lacan).

A tese de Badiou - a teoria do ser-evento - retoma pontos dessas três vertentes. De Heidegger, vem a idéia de que é através da ontologia que se devem derivar as questões da filosofia. Da lógica matemática, vem a adoção de orientações formais novas para o pensamento. Das novas teorias do sujeito - seja a marxista, seja a psicanalítica - vem a certeza de que hoje não se pode mais fazer ontologia sem a idéia de sujeito. Badiou, portanto, se inscreve numa espécie de "confluência muito particular" dessas três vertentes.

A potencialidade da matemática hoje está em se falar do sujeito enquanto processo. O objetivo de sua ontologia aqui é então articular a matemática, a ciência do ser, às doutrinas do evento, que é o discurso ou o "o-que-não-é-o-ser-enquantoser". Cabe aqui um raciocínio paralelo: $O$ ser, para Badiou, está para a metafísica assim como o evento está para o discurso. Para dar conta desse raciocínio, o autor reconstrói a noção de sujeito e conseqüentemente a noção de verdade, caminhando da ontologia matemática ao evento no discurso. Assim, o livro de Badiou "funda uma doutrina efetivamente pós-cartesiana, e até pós-lacaniana, daquilo que, para o pensamento, ao mesmo tempo des-liga a conexão heideggeriana do ser e da verdade e institui o sujeito, não como suporte ou origem, mas como fundamento do processo de uma verdade"(pág. 21).

Dentro da matemática, a categoria escolhida para sintetizar seu empreendimento filosófico é a categoria do genérico, do lógico norte-americano Paul Cohen. Nem o múltiplo puro de Cantor, nem o construtível de Gödel dariam conta de seus 
WACHOWICZ T. C. Uma fundamentação da noçāo...

objetivos. Para Badiou, procedimentos genéricos, como o amor, a arte, a ciência e a política, prendem a verdade à instância no tempo. Esse procedimento é o que ele chama de sujeito. Um sujeito é, então, o que certifica uma verdade localmente, e o que sustenta um procedimento genérico.

A opção metodológica de Badiou é escrever o livro em oito capítulos, que se dividem em trinta e sete "meditações". Estas são de três tipos, como se o livro fosse um todo formado por três, um "três-em-um": as meditações conceituais, que ligam e desdobram os conceitos para o pensamento filosófico proposto; as meditações textuais, que interpretam textos da filosofia e da literatura (Platão, Aristóteles, Espinosa, Hegel, Mallarmé, Pascal, Höderlin, Leibniz, Rousseau, Descartes e Lacan); e as meditações metaontológicas, que se apóiam no discurso matemático, ou ontológico (os axiomas da teoria de conjuntos, a teoria dos números ordinais, os números cardinais, o construtível, o genérico e o forçamento).

A leitura do trabalho de Badiou é exigente: requer tempo e paciência. No entanto, é um prato cheio para quem quiser introduzir-se no discurso lógico através de uma perspeciva discurso-filosófica. $O$ autor desenvolve, por exemplo, a teoria de conjuntos em seus axiomas com comentários filosóficos; estabelece, também a distinção entre pertença $(\epsilon)$ e inclusão $(\subset)$, construindo um raciocínio paralelo: a pertença está para a apresentação (situação) e para a estrutura, assim como a inclusão está para a representação (estado da situação) e para a meta-estrutura. Com toda a construção matemática, o autor chega, principalmente nos capítulos 5 e 6, à noção de evento.

A idéia central é a de que o evento é indecidível, inapresentável e imprevisível por natureza: filosófica e matemática. A intuição primeira de que a entidade evento estaria numa espécie de limite entre a pragmática e a semântica, falando agora em termos lingüísticos, foi confirmada pela conceituação desenvolvida por Badiou. $\mathrm{O}$ evento, para ele, é o impasse da ontologia matemática. No momento em que ele surge, surge também o seu paradoxo - de que ele não pertence ou de que ele pertence a si mesmo - e sua indecidibilidade. O evento é pensado a partir da situação histórica, mas só pode constituir-se representável se houver uma decisão - a de que ele pertence a si mesmo -, o que desencadeia a série de eventos que vai constituir o tempo. O tempo, nesse sentido, seria o elemento que garante a existência do evento, que o tira da inapresentabilidade ou do caos.

É interessante observar aqui que o tempo faz o papel de "ordenação" da natureza. É uma idéia que está presente desde a mitologia grega, no mito de Chronos, até em algumas teorias da física quântica, como das estruturas dissipativas, de Prigogine 1996. Quer dizer, mais do que um suporte filosófico para o trabalho semântico da leitura temporal, percebemos que o par evento/tempo percorre universalmente o pensamento humano.

Com vistas à sua nomenclatura, Badiou denomina "sítios eventurais" as situações históricas. Matematicamente, os sítios - o mínimo concebível para o efei- 
WACHOWICZ T. C. Uma fundamentação da noção...

to da estrutura - pertencem à situação, mas o que lhe pertence já não pertence à situação. Nesse sentido, eles estão num impasse formal, que começa a se desenhar. $\mathrm{Na}$ comparação entre história e natureza, Badiou desenvolve o seguinte raciocínio: a história é naturalizável, mas a natureza não é historicizável. Lembremos que "natureza", para Badiou, é a ontologia matemática construída com a idéia de conjuntos. Assim, os sítios eventurais estão para a história assim como os conjuntos estão para a natureza. Há sítios eventurais em situação (representação), mas não situação eventural. Podemos pensar a historicidade de certos conjuntos, mas não podemos pensar uma História. Daí vem a idéia de que a definição dos sítios eventurais é local, ao passo que das situações naturais é global. Imediatamente: as situações naturais vêm das situações históricas. Em termos lógicos, os modelos de interpretação vêm das situações reais.

Se o conceito de evento advém do conceito de sítio eventural, é necessário se construir aqui um "matema", ou formalização, desse conceito. Seja $S$ a situação, e $X \in S$ (X pertence a $S, X$ é apresentado por $S$ ) o sítio eventural. e (leia-se o evento de sítio $X$ ) se escreve assim: $e_{x}=\left\{x \in X, e_{x}\right\}$. Em termos descritivos, um evento de sítio $\mathrm{X}$ é um conjunto tal que é composto, por um lado, pelos elementos do sítio, e, por outro, por ele mesmo.

Um exemplo citado pelo autor é o da Revolução Francesa. Como definir esse evento? Ele é tudo o que a época fornece de traços e fatos: os camponeses, os soldados, a guilhotina, os preços de subsistência, os efeitos de retórica, os massacres, os espiões ingleses, o teatro, a Marselhesa; mas ele é também o termo axial da própria revolução. "Da Revolução Francesa como evento é preciso dizer ao mesmo tempo que ela apresenta o múltiplo infinito da seqüência dos fatos situados entre 1789 e 1894, e, ademais, que ela apresenta a si mesma como resumo imanente e traço-de-um de seu próprio conjunto"(p. 149).

Há um paradoxo que acompanha a definição de evento construída a partir de sítio eventural. Por um lado, pode-se "decidir" que o evento não pertence a ele mesmo, o que inviabilizaria a formalização acima. Assim, o evento não apresenta senão os elementos de seu sítio, não podendo ser uma entidade única. $O$ que tem lugar é só o lugar, e não o evento. No exemplo desenvolvido, "Revolução Francesa" seria só uma pura palavra. Por outro lado, pode-se decidir que o evento pertence a ele mesmo. Esta foi a opção que originou a formalização acima. O evento é, então, mais do que os elementos de seu sítio, é também um conceito que os agrupa, ou o seu próprio nome. "Revolução Francesa", além de uma simples expressão, significa um evento "unificável".

As consequiências dessa segunda opção são bastante fortes. Ela reassegura a possibilidade de conceber o evento como conjunto. Se o evento advém da historicidade, a primeira inclinação é pensá-lo fora da ontologia matemática. Mas há como reassegurá-lo. Em teoria de conjuntos, o axioma de fundação é a regra que suporta essa idéia. Formulado por Zermelo bastante tardiamente, o axioma prevê 
conjuntos de outra natureza: ele estabelece que todo conjunto é histórico, ou seja, contém ao menos um sítio. Isso quer dizer que o conjunto contém um outro conjunto histórico cujos elementos não pertencem ao primeiro. Formalmente, o axioma de fundação tem a seguinte tradução: $(\forall \alpha)[(\alpha \neq \varnothing) \rightarrow(\exists \beta)[(\beta \in \alpha) \wedge(\beta \cap \alpha=\varnothing)]]$.

Toda essa discussão é exemplificada metaforicamente por Badiou na poesia, especialmente em Mallarmé, no poema Um lance de dados. Na sua leitura, tem-se a visão de uma pluma - a vela de um navio - que, guiada pelo movimento suave do vento, não sabe onde pousar. Algo a situa finalmente: a imagem decisiva do navio. O poema $U m$ lance de dados, para Badiou, "organiza uma assombrosa série de transformações metafóricas em torno do tema do indecidível" (p. 159), assim como o faz o evento.

Mas há uma aposta na existência do evento; algo vai legislar, sem lei, a sua existência. Badiou vai expor para isso a idéia de intervenção. A legitimação do evento vai se dar por um caminho de intervenção, enxergando a disciplina do tempo como o fator rearranjador da teoria. A "intervenção" é todo procedimento evidentemente licenciado matematicamente - pelo qual um conjunto é reconhecido como evento. A intervenção, num certo sentido, devolve ao evento a propriedade de pertencer à situação. Daí vem o paradoxo da intervenção: ela reconhece o evento como forma eventural e ao mesmo tempo impõe sua decisão relativa de sua pertença à situação. É o ato de nomeação do evento que permite essa decisão. Então, nomeação é "fazer nome de um elemento inapresentado do sítio para qualificar o evento de que esse sítio é o sítio" (p.167).

Uma das características da nomeação - a mais interessante para nós - é que a intervenção só é possível na possibilidade de ela agir sobre um outro evento. Assim, a intervenção é o que apresenta um evento para o advento de um outro. "Isso quer dizer que a teoria da intervenção é o nó de toda teoria do tempo"(p.171). O tempo é a própria intervenção, pensada como distância entre dois eventos.

Em termos formais, a intervenção surge com o axioma da escolha. Se o axioma de fundação - que diz que todo conjunto contém um subconjunto cujos elementos não pertencem ao primeiro - gerou polêmica na comunidade matemática do início do século (possivelmente até hoje), o axioma de escolha gerou uma acirrada batalha matemática jamais vista. A idéia do axioma é que, dado um conjunto de subconjuntos, existe um conjunto composto de um representante de cada um dos subconjuntos não vazios cuja apresentação é assegurada pelo primeiro conjunto. Em outras palavras, pode-se "escolher" um conjunto formado pelos representantes dos subconjuntos do primeiro. Na linguagem lógica, $(\alpha)(\exists \phi)[(\beta \in \alpha) \rightarrow$ $\phi(\beta) \in \beta]$. É a função f de escolha que faz a seleção do conjunto dos representantes, tal como o povo que elege os seus representantes na Câmara dos Deputados.

Após toda a construção teórica das noções necessárias, Badiou chega à noção de verdade e de sujeito. A partir disso, então, surge definitivamente o seu diálogo com a psicanálise, de maneira especial com Lacan. Na verdade, ele contrapõe-se 
à noção de verdade de Lacan, segundo a qual o sujeito é advindo do vazio e tem suas verdades condicionadas à sua experiência. A verdade para Badiou está ligada a um indiscernível - contrariamente aos postulados de Leibniz -, o genérico, cuja aproximação um sujeito sustenta a partir na nomeação do evento. $O$ sujeito, assim, se submete às verdades genéricas, ou ideológicas, num fim último, tal como a ideologia marxista prevê.

É fim do livro é que se pode visualizar diretamente o compromisso de Badiou com uma filosofia pós-marxista. Ele faz todo um malabarismo matemático para chegar a uma noção em teoria de conjuntos que condicione as verdades do sujeito ao meio ideológico que vive. É um trabalho de peso e de respeito. Mais do que isso, é um trabalho que pode ilustrar uma noção de lógica atual que deve entrar definitivamente no pensamento dos lingüistas. A lógica não se constitui de uma só linguagem, mas sim de várias alternativas que podem, inclusive, dentre elas, tanger a questão do sujeito. Falar de lógica, hoje, é pois abrir um leque de múltiplas alternativas para o tratamento abstrato das questões naturalmente observáveis. Assim como as ciências, as artes e as filosofias assumiram várias facetas neste século XX, também as linguagens lógicas o fizeram.

Com relação à noção de sujeito, há algumas preliminares que necessitam ficar claras. Para Badiou, sujeito é "toda configuração local de um procedimento genérico em que uma verdade se sustenta"(p. 307). Daí já se podem depreender as idéias de que sua noção de sujeito tem definitivamente todo um construto lógico subjacente. Além disso, é um sujeito "genérico", ou seja, ligado a uma consideração geral em que se sustenta a noção de verdade. Mais do que isso, é um sujeito atado ao condicionamento geral das idéias: é um sujeito ideológico.

Há então um possível resumo das "capacidades" do sujeito: ele é "aquilo que, instância finita de uma verdade, efetuação discernida de um indiscernivel, força a decisão, desqualifica o desigual e salva o singular"(p. 320). É por essas características que o sujeito salva o evento, ou a entidade matemática comprometida com o histórico e real. Nesse momento, pode-se concluir a respeito do título do livro - o ser c o evento. O ser matemático não tem relevância para ele, o que importa é o evento. Mas o ser aqui assume a agentividade do sujeito (procedimento genérico): o ser (sujeito) resgata o evento para atribuir-lhe verdade.

\section{Santos 1997}

O trabalho de Santos chama a atenção para a sua capacidade de transitar por assuntos e áreas variadas - da filosofia à sociologia -, explorando fortemente uma quantidade inigualável de citações e referências. 
Seu objetivo no livro se divide em dois: 1) o de definir o objeto da geografia, em suas categorias de análise, bem como as questões epistemológicas que derivam dessa nova proposta; 2) e o de discutir a noção de globalização à luz de suas novas categorias, inaugurando, dentro da geografia, focos de resistência à sua força homogeneizadora. O que nos interessa de perto é, na verdade, a noção de evento construída paulatinamente na esteira desse primeiro objetivo.

Junto à noção de evento, são construídos outros conceitos importantes à visão de toda a proposta de análise: técnica, espaço (sistemas de objetos e sistemas de ação), tempo e evento.

Santos constrói a idéia de técnica para dar unidade entre tempo e espaço. Técnica é o uso que se faz dos objetos através do tempo. Assim, a maneira como a unidade entre tempo e espaço vai dando-se é revelada através da história das técnicas: a técnica agrícola, a industrial, etc. A técnica, nesse sentido pragmático, permite com que o tempo seja empiricizado, tornando-se verdadeiro, real, inseparável da matéria corpórea e indissociável do espaço. O interessante ainda é que Santos liga os conceitos entre si. A técnica, segundo ele, é um dado constitutivo do espaço e do tempo operacionais - o que sinaliza os "objetos" - e do objeto e do tempo percebidos - o que sinaliza as "ações".

A partir daí, o conceito de espaço é pormenorizado como sendo uma interação dinâmica (posto que espaço pressupõe o tempo, e vice-versa) entre sistemas de objetos e sistemas de ações.

Falar em sistemas de objetos é falar de uma configuração territorial de bases fixas; e falar de sistemas de ações é falar de relações sociais que, naturalmente, têm bases dinâmicas. Logo, como espaço é interação entre objetos e ações, ele não pode ser concebido estaticamente, mas essencialmente como dinâmico. Assim, na definição de técnica, os subconceitos de espaço, aqui, são interdependentes. Então, os objetos não são essencialmente estáticos porque eles se definem pelas ações e viceversa.

Aparecem, a partir, e dentro dos conceitos de técriica e espaço, considerações interessantes que dão novos contornos teóricos e empíricos ao objeto de estudo em questão. Inicialmente, nessa interação indissociável entre objetos e ações, emerge a questão da intencionalidade. Fica inevitável, então, o seguinte raciocínio: as relações sociais revelam as ações, que revelam os sujeitos, que revelam a intencionalidade. Logo, o diálogo teórico agora é com a psicanálise. É aqui que Santos se assenta para incrementar a noção de intencionalidade. Localizada em episódios, ela é naturalmente determinada e analisável. Essa opção é sem dúvida melhor para a geografia, pois espaços ganham maior poder para defini-la.

Além da idéia de intencionalidade, revela-se aqui o cerne da construção do conceito de evento. A ação, por ter um caráter essencialmente momentâneo e interferência fortemente subjetiva, perde relevância na teoria. É necessário, agora, um 
WACHOWICZ T. C. Uma fundamentação da noção...

conceito que vá do momentâneo a outros feixes de tempo, e de forma contrastiva, e que vá do espaço a outros feixes do espaço. Surge a categoria do evento, agora de natureza essencialmente dialética. Santos o situa quase que poeticamente, como se fosse uma "forma" que detém vida, ou um "palimpsesto" que detém história de várias ações. Ou seja, o espaço, agora definido com o evento, é como se fosse um palimpsesto mutante.

Inaugurando a sua noção de evento, Santos pretende dar à geografia uma noção de totalidade como categoria analítica. Quer dizer, o tempo como um todo não é um tempo isolado de seu conjunto - passado e futuro. Vale lembrar que o tempo aqui, atrelado à noção de espaço, lembra o tempo da teoria da relatividade: "Na verdade, trata-se de um instante no tempo dando-se em um ponto no espaço, (...) numa teoria da natureza que leve em conta a relatividade" (p. 115). Porém, muitas vezes o autor o assume irreversível e contínuo: "Alinhados cronologicamente, os eventos se sucedem uns aos outros. Daí poder-se falar numa ordem de eventos, sua ordem temporal" (p. 123). Uma leitura aos olhos da lógica temporal, ou teorias do tempo, seria bem-vinda.

Num outro sentido, o espaço como um todo não é só lugar isolado e congelado, mas um processo comparativo entre sistemas de objetos e sistemas de ações: todos mutáveis. Talvez a palavra-chave nesse momento seja justamente "processo". Não só em relação ao espaço, mas a todas as outras categorias analíticas, vale a idéia de "processo de..." e de "totalidade de...". Seu objeto geral de estudo passa a ser agora um processo de totalização.

Santos ainda tece considerações mais de fundo sociológico quando, no capítulo 5, chama a atenção para o papel da divisão do trabalho e repartição de recursos para a totalidade do espaço. São estes dois feitos que constituem o espaço, em suas formas de funcionamento e objetivação. Quer dizer, política econômica e política do trabalho, entre um sem número de fatores, dinamizam o espaço.

Finalmente, no capítulo 6, a noção de evento ganha detalhamento. Santos recupera sua indissociabilidade com o tempo e o seu caráter relativo. Em suas palavras, "um evento é um instante no tempo e um ponto no espaço"; ao mesmo tempo, são todos presente, podendo ser relativizados à sua anterioridade e à sua posterioridade. Semelhante à singularização de uma ação da pragmática dos atos de fala (Searle, Austin), o evento aqui também é uma ação e vice-versa. Neste ponto, o autor ensaia uma tipologia de eventos, citando eventos naturais e eventos históricos. Pressupondo a intencionalidade das ações, são os eventos históricos, ou sociais, que ocupam a sua preocupação.

Santos ainda complexifica o tratamento à medida em que expõe as "características" do evento, todas baseadas em uma certa variabilidade: sua duração é complexa e variável; sua extensão é local ou ramificada; os eventos podem ter escalas diferentes e se sobrepor. Enfim, há uma rede de critérios de análise considerável. 
WACHOWICZ T. C. Uma fundamentação da noção...

Nos exemplos citados pelo autor , isso fica mais claro: os fatos da agricultura mostram como eventos podem ser interdependentes. Outros exemplos: a meteorologia e a economia.

Enfim, o evento assume diferentes facetas - as sucessões/as coexistências, a universalidade/a localidade -, que fazem com que o mundo seja visto como um "caleidoscópio de situações". Lembrete: este caleidoscópio está inserido dinamicamente no desenrolar do tempo. Em lingüística, essa concepção multifacetada dos eventos interessa para análise de periodos complexos ou perspectivas textuais.

$\mathrm{Na}$ terceira e quarta partes do livro, a preocupação se volta à discussão sobre a globalização. Mais um ensaio analítico do que um tratado epistemológico, como foram as partes primeira e segunda, aqui se quer desenvolver "uma geografia para o presente", ou seja, para o mundo vivendo à luz da globalização.

A rapidez das informações torna hoje os sistemas mais únicos. Há unicidade de técnicas, do tempo, dos objetos e ações, e a conseqüente simultaneidade de eventos. Ou seja, tudo acontece rápido, ao mesmo tempo e quase da mesma maneira. Porém, o que permanece mais constante é o lugar e as suas particularidades - um diferencial junto à efemeridade dos eventos. Aqui origina-se a tese central de Santos, segundo a qual a natureza dos lugares, complexa e heterogênea, cria resistência à ação racionalizante e homogeneizante da globalização.

Todos esses tópicos vão construindo um teor programático ao texto de Santos, em que se percebe a forte preocupação com a necessidade de relações mais humanas/ imprevisíveis/ naturais. Enfim, a racionalidade do espaço, e de outras entidades por ele consideradas, provocada pelos movimentos homogeneizantes da globalização, são combatidos pela força dos lugares. Santos propõe assim que há uma resistência, advinda do espaço geográfico, que reverte o caminho da ordem global para a ordem local. As forças particulares de cada lugar fazem com que a hegemonia não seja tão hegemônica assim, e a globalização não seja tão efetiva quanto parece.

\section{Comparações teóricas e conseqüências lingüísticas}

Na tentativa de estabelecer fundamentação filosófica para a noção de evento da linguística, assumimos principalmente que a origem direcionada freqüentemente a Davidson é inaugural, mas não suficiente. Isso se deve ao fato de que, se o objetivo lingüístico é um tratamento composicional, a noção de evento deve se complexificar. A garimpagem nas idéias de Badiou e de Santos nos viabilizam esses objetivos.

São três pontos, presentes nas três teorias acima, que permaneceram visí- 
veis na "peneira teórica": 1) a idéia de evento como entidade unificadora - de outras subentidades; 2) a idéia de evento como portadora de uma ação do sujeito, ou agentividade, e de intencionalidade; e, por fim, 3) a idéia de evento como semanticamente existente, mas imprevisível por natureza.

\section{$O$ evento como entidade unificadora}

Na medida em que Davidson reverte o raciocínio de Kenny, da poliadicidade variável das sentenças de ação, para a opção da predicação sobre a entidade evento, ele assume subinformações sobre ele: a informação de tempo, de espaço, de instrumento, etc. Essas expressões, que a gramática tradicional chama de informações adverbiais, parecem compor um conjunto de outras marcas que definem o evento, como se ele fosse uma entidade lógica de unificação de especificações "dêiticas".

O mesmo raciocínio é encontrado em Badiou, agora de forma assumidamente teórica e desenvolvida. Para chegar até o conceito de genérico, e consequientemente ao sujeito e à verdade, Badiou deve definir o evento. Ele advém de um sítio eventural, que nada mais é do que uma situação histórica, com relações de tempo, de espaço, de indivíduos, etc. - essencialmente contingente, imprevisível e dinâmica. Para a teoria do ser-evento, é necessário que haja uma nomeação - um procedimento de intervenção, ou o sujeito - que inaugura a participação do evento num modelo de representação. $O$ nome do evento $\left(e_{x}\right)$ permite o seu ingresso na ontologia, mas, recuperando a definição matemática de Badiou, se $e_{x}=\left\{x \hat{I} X, e_{x}\right\}$, um evento é todo $\mathrm{x}$ que compõem o seu sítio e também é o seu nome próprio, ou seja, todo evento pertence a ele mesmo. Mas esses $x$ que compõem o sítio eventural nada mais são também do que as especificações que o definem: os lugares, os indivíduos, os "subeventos", etc. Porém, há uma questão aqui que diverge da perspectiva lingüística de Davidson: o tempo surge da sucessão de eventos, no nível teórico. A intervenção que inaugura o evento em relação a outros inaugura, ao mesmo tempo, a teoria do tempo. Logo, no lugar de ser uma informação "dêitica", como o é em Davidson, o tempo para Badiou é teoricamente indissociável ao evento. As implicações lógicas que derivam dessa distinção fogem ao alcance filosófico deste trabalho. Preferimos reagir de forma redutora e pensar que o tempo, num e no outro caso, está como subespecificação do evento.

Junto com o tempo, o espaço, para Santos, também compõe a rede de subunidades do evento. E espaço ainda é sistema de objetos e sistema de ações juntos, dinâmicos e mutáveis. Há uma indissociabilidade, em Santos, entre tempo e espaço - ações e objetos. E essa unificação deve ganhar nome, pois é num certo sentido uma abstração, assim como acontece também com o evento de Badiou. $O$ raciocínio parece o mesmo: o evento toma força abstrata em Santos pois unifica informações 
WACHOWICZ T. C. Uma fundamentaçāo da noção...

das suas categorias de análise, assim como em Badiou ele surge na representação abstração - através de um nome que designa os elementos do sítio eventural. Vale lembrar que, em Santos, os objetos que compõem o espaço são os indivíduos pacientes que interagem nas ações dos indivíduos agentes e intencionais.

$\mathrm{Na}$ lingüística, a especificação das subunidades do evento pode ser interessante à idéia da leitura composicional dos significados de sentenças. A questão aspectual da forma progressiva do português, por exemplo, pode ter alguma alternativa de análise nesse sentido. Se a sentença Está passando o ônibus denota, num primeiro momento um evento, a mesma sentença, com modificação temporal - De minuto a minuto está passando o ônibus -, denota uma sucessão de eventos. A mesma variação de leitura aparece em modificações na expressão do objeto direto: a sentença Ele estava dando a entrevista, de um só evento, torna-se "iterativa" em Ele estava dando as entrevistas. Nesses casos, as expressões de tempo e os termos dos indivíduos envolvidos no(s) evento(s) interagem composicionalmente na interpretação.

\section{$O$ evento como entidade portadora de agentividade e intenciona- lidade}

É traço forte da exposição de Davidson que o evento, sendo a contraparte lógica de sentenças de ação, requer agentividade e conseqüente intencionalidade, embora o autor assuma que esta correlação nem sempre é direta. Nem todo evento é intencional. Em língua natural isso fica evidente: em sentenças como João bateu no muro, a intenção pode não existir. João pode estar dirigindo um carro $\mathrm{cm}$ que repentinamente surgiu um defeito mecânico que provocou a batida. Naturalmente, o problema do sujeito e da intencionalidade é muito mais profundo e filosoficamente comprometido do que a maneira como este trabalho o apresenta. Mas há, contudo, perspectivas, mesmo dentro da lingüística, que podem responder a algumas questões.

É muito interessante, por exemplo, a proposta de combinações de traços de papéis temáticos, ou propriedades temáticas, de Dowty $1989,1991^{3}$, por exemplo, para se definir agentividade sem intenção, ou experiencialidade sem intenção, por exemplo. Nessa proposta, é possível definir papéis temáticos através de uma combinatória de traços temáticos que envolvem os indivíduos de uma sentença. Mas o interessante disso tudo é que há, tanto em Davidson como em autores lin- 
güistas, um sujeito presente na abordagem teórica, ou um sujeito presente na noção de evento.

Em Badiou, a intencionalidade não é explicitamente tratada, mas revela-se subjacente à sua teoria do sujeito. Se esse sujeito é um procedimento genérico, singular e localizado, que nomeia um evento a partir da situação de um sítio eventural, ele é absolutamente condicionado ideologicamente. Badiou situa esse condicionamento poeticamente nas situações do amor, da arte, da ciência e da política. E mais, não há como definir ou prever matematicamente o que o sujeito faz, mas há como definir e prever que ele faz, pois o procedimento genérico que é o sujeito é singular, ou um estatuto local de um procedimento.

A intencionalidade se revela mais presente em Santos, à medida em que ele prevê, em seu sistema de categorias, o sistema de ações compondo o espaço. Retomando a idéia de que as relações sociais contêm ações, que contêm sujeitos, que contêm intenções, Santos considera esses traços perfeitamente passíveis de análise e teorização. Porém, paralelamente a Badiou, os ações são singulares, localizadas e subjetivas. Suas categorias interagem dinamicamente com a assumida subjetividade. Em sua análise sociológica, isso caracteriza o espaço das ações como foco de resistência à previsibilidade e homogenização da globalização.

Tomando agora uma visão mais geral, a questão do sujeito, que tanto assusta algumas concepções de perspectivas formais de teorias lingüísticas, vem agora mostrar-se passível de tratamento teórico. Não há motivos para deixá-lo de lado. Adotando a proposta de Badiou, até por ser a mais formalizada, é possível definir um sujeito a partir de uma perspectiva de teoria de conjuntos, e o mais assustador, a partir de uma teoria de conjuntos que contemple definições ideológicas - e os

axiomas de fundação e de escolha colaboraram para isso. É possível igualmente considerá-lo teoricamente na semântica de língua natural. Julgo que uma semântica nominal, ou de indivíduos, aliada a uma boa teoria de papéis temáticos, podem talvez tanger esses pressupostos.

\section{Um evento que existe, mas não é previsto}

Com todo o desenvolvimento teórico de Badiou, Santos e mesmo de Davidson, fica uma idéia subjacente (talvez também explícita algumas vezes) a toda a discussão, que é a de que o evento parece ser um arranjo-em-um de uma situação pragmática. Realmente o é. Nos itens anteriores, essa idéia é reforçada através das noções unificadoras e subjetivas do evento. Em outros termos, o evento parece representar um "ato de fala", com todas as variantes e implicações que isso pode trazer.

Não se trata, no entanto, de propor uma teoria pragmática. Talvez a nomen- 
clatura aqui seja o que menos interessa. Trata-se, substancialmente, de uma entidade lógica que possa resgatar noções por vezes negligenciadas nas teorias, tais como, justamente, a complexificação do tempo, do espaço, dos indivíduos, os quais estão ligados aos seus respectivos papéis temáticos - ou combinatórias temáticas. Essa subespecificação complexificada interage - composicionalmente - de forma a necessitar da ancoragem do evento.

Disso, vem imediatamente a idéia de evento como entidade singular e imprevisível. Cada arranjo composicional é resultado da intervenção de um sujeito, num ato particular. Teoricamente, isso quer dizer que não há regras que prevejam o evento; só há como provar que ele existe.

Essa idéia está fortemente assumida em Davidson, à medida em que ele, citando Reichenbach, assume que não há teoricamente como descrever um evento a priori, mas há como prever que ele existe. Badiou, mais fortemente ainda, defende um evento como entidade indecidível, inapresentável e imprevisível por natureza. Ele passa a existir através de uma intervenção, ou uma nomeação. Assim, nada pode nos dizer previamente como ele é, nada pode prevê-lo. A única certeza que a teoria nos dá - em Badiou, pelas definições de procedimento genérico, intervenção, etc. - é que ele pode existir. A singularidade do evento também é posta por Santos, embora menos explicitamente ou teoricamente que Badiou, quando ele o define como sendo efêmero, imprevisível e subjetivo.

No entanto, a idéia não é absolutamente a de deixar de lado toda tentativa de representação genérica dos significados. Absolutamente. A idéia é, justamente, uma inversão de raciocínio: não há como representar significados, visto que eles são imprevisíveis mesmo, mas há sim como representar relações de significação. Essas relações de significação são perfeitamente passiveis de formalização, e a perspectiva lógico-conjuntista está aí para dar conta disso. Em Borges 1998, essa questão ganha maior discussão e fundamentação à medida em que o autor define "modelo" teórico para a lingüística, a partir desse raciocínio. Um modelo nada mais é do que uma construção teórica que define as relações de significação.

\section{Conclusão}

De todas essas noções que redefinem e complexificam o evento, vem a questão de como tratá-lo numa semântica de língua natural. Há algumas alternativas mais recentes que evidenciam o tratamento de eventos como alternativas viáveis. Parsons 1989 por exemplo, propõe uma alternância de predicação sobre eventos, através dos predicados $c u l$ - de culminância - e hold - de realização - para a distinção entre eventos de culminância ou mudança de estado, e eventos de atividade ou 
não mudança de estado, respectivamente. Por outro lado, num problema mais aprofundado, como o aspecto, Bonomi 1997 apresenta uma alternativa de quantificação sobre eventos para distinguir sentenças perfectivas, com quantificação existencial, das sentenças imperfectivas, com quantificação universal.

Porém, numa perspectiva mais geral, Link 1997 faz uma proposta de modelo de interpretação para língua natural contemplando a entidade evento, através de um domínio de eventualidades $\mathrm{E}$, que mapeiam o subdomínio de espaços temporais $\mathrm{H}$ e o subdomínio de intervalos de tempo $\mathrm{T}$, através das funções $t$ e $\mathrm{s}$, respectivamente. O conjunto das eventualidades está também correlacionado ao domínio dos indivíduos A - termos singulares, plurais, termos de massa, coletivos, etc. - e também a um conjunto de papéis temáticos $\mathrm{R}$. Ou seja, cada evento e de $\mathrm{E}$ tem um conjunto correspondente de papéis temáticos. E os elementos de $\mathrm{A}, \mathrm{E}, \mathrm{T}$ e $\mathrm{H}$ estão relacionados sob tipos específicos de reticulados - conjuntos cujos elementos têm uma determinada ordenação. $O$ modelo de interpretação de Link ganha, então, a seguinte forma: $\mathrm{M}=\langle\mathrm{A}, \mathrm{E}, \mathrm{T}, \mathrm{H}, \mathrm{R}, \mathrm{t}, \mathrm{s}\rangle$. A questão que fica é a seguinte: podemos visualizar a complexificação da noção de evento nesse modelo de interpretação? Há como estabelecer composicionalidade aqui, através de relações entre os domínios?

Outra questão que torna-se interessante em semântica de eventos é a variabilidade de considerações a respeito da classificação de eventos, ou classes aspectuais, denotados pelas sentenças de língua natural. A partir de Vendler 1967, as conhecidas classes estado, atividade, accomplishment c achievement ganharam corpo na análise semântica. Há, atualmente, a preocupação teórica voltada à mudança de classe aspectual de acordo com a estrutura da sentença. Smith 1997, por exemplo, sinaliza uma combinatória de informações para rearranjar a classificação de sentenças. Essas informações são de natureza morfológica, sintática e semântica e formam um "bolo" combinatório que se define singularmente para cada sentença. Ora, é assumidamente uma perspectiva composicional. Resta apenas investigar a noção de evento que está por trás.

Naturalmente, a investigação linguiística não se limita a essas referências. Há muito ainda por fazer. No entanto, julgamos ser pertinente essa "viagem" filosófica - objetivo deste texto - para que possamos ter consciência do que estamos falando quando abordamos uma teoria de eventos na linguística. $O$ evento pode ser mais do que imaginamos. Esperamos que esse texto possa ter provado isso. 
WACHOWICZ T. C. Uma fundamentação da noção...

\section{RESUMO}

Tomando como base Davidson 1980, Badiou 1996 e Santos 1997, o objetivo deste trabalho é propor uma fundamentação mais clara e complexa da noção de evento para a lingüística, mais especificamente para a semântica de eventos. Tal análise sugere uma alternativa de tratamento composicional de sentenças de língua natural.

Palavras-chave: semântica, evento, composicionalidade.

\section{ABSTRACT}

With Davidson 1980, Badiou 1996 and Santos 1997, the aim of this paper is to present a clearer and more complex idea to the notion of event in linguists, specially in event semantics. This analysis suggests an alternative to the composicional treatment of natural language sentences.

Key words: semantics, event, compositionality.

\section{REFERÊNCIAS}

BADIOU, Alain. O ser e o evento. Trad., M.L.Borges. Rio de Janeiro: Jorge Zahar Ed, 1996.

BONOMI, Andrea. Aspect, quantification and when-clauses in italian. Linguistics and Philosophy. 20, p. 469-514, 1997.

BORGES NETO, José. Fundamentos de semântica formal (a semântica de Montague). Tese de Titular. UFPR, 1998.

DAVIDSON, Donald. The logical form of action sentences, Essays on actions and events. Oxford: Carendon Press, 1980.

LINK, Godehard. Algebraic semantics in language and philosophy. CSLI Publications, 1997.

PARSONS, Terence. The progressive in English: events, states and process, Linguistics and Philosophy, 12, p. 312-241, 1989.

PRIGOGINE, Ilya. O fim das certezas : tempo, caos e as leis da natureza. Trad. Roberto Leal Ferreira. São Paulo: Ed. da UNESP, 1996.

ROTHSTEIN, Susan (ed.). Events and grammar. Kluwer, 1998.

SANTOS, Milton. A natureza do espaço -técnica e tempo, razão e emoção. 2. ed., São Paulo: Hucitec, 1996.

SMITH, Carlota S. The parameter of aspect. 2. ed., Kluwer, 1997.

WYNER, Adam Zachary. Subject-oriented adverbs are thematically dependent, ROTHSTEIN, S. (ed.). Events and grammar. Kluwer. 1998. 